\title{
Sex Chromosome Drive
}

\author{
Quentin Helleu, Pierre R. Gérard, and Catherine Montchamp-Moreau \\ Laboratoire Évolution Génomes et Spéciation, CNRS UPR9034, Gif-sur-Yvette, France and Université \\ Paris-Sud, Orsay, France \\ Correspondence: catherine.montchamp@legs.cnrs-gif.fr
}

Sex chromosome drivers are selfish elements that subvert Mendel's first law of segregation and therefore are overrepresented among the products of meiosis. The sex-biased progeny produced then fuels an extended genetic conflict between the driver and the rest of the genome. Many examples of sex chromosome drive are known, but the occurrence of this phenomenon is probably largely underestimated because of the difficulty to detect it. Remarkably, nearly all sex chromosome drivers are found in two clades, Rodentia and Diptera. Although very little is known about the molecular and cellular mechanisms of drive, epigenetic processes such as chromatin regulation could be involved in many instances. Yet, its evolutionary consequences are far-reaching, from the evolution of mating systems and sex determination to the emergence of new species.

Misis eiotic drivers are selfish genetic elements that subvert Mendelian segregation during gametogenesis for their own benefit. They are passed on to most, if not all, of the functional gametes produced by heterozygotes. Therefore, drivers can increase in frequency and invade populations even if they reduce individual fitness, which is usually the case. The drivers are typically expressed in one sex, of which fertility is impaired. This also has deleterious consequences for the opposite sex and is expected to promote adaptations to counteract drive through sexual selection and sexual conflict. Furthermore, sex-linked meiotic drivers expressed in the heterogametic sex typically lead to biased offspring sex ratios, which represents an additional cost and can exacerbate the sexual conflict.

Morgan et al. (1925) were the first to observe sex-biased offspring, which turned out to be caused by a sex-linked meiotic driver. Unfortunately, the Drosophila affinis strain was lost before any conclusive study could be performed. Later, Gershenson (1928) found that the offspring of some Drosophila obscura males were female biased. He showed that these males carried an X-linked genetic element (hereafter "sex ratio" or $S R$ ) responsible for the sex-ratio distortion, and showed that the $S R$ did not affect the viability of the male offspring but acted as a gametic killer of Y-bearing sperm. Gamete killing or disabling is observed in males; in females, meiotic drive is usually a result of centromere competition for access to the egg.

In its original definition (from Gershenson's work and others), the term meiotic drive applies to the consequences of the mechanics of the meiotic divisions (Sandler and Novitski 1957). Here, under the term "sex chromosome drive," we will include more broadly any case of

Editors: William R. Rice and Sergey Gavrilets

Additional Perspectives on The Genetics and Biology of Sexual Conflict available at www.cshperspectives.org

Copyright (C) 2015 Cold Spring Harbor Laboratory Press; all rights reserved; doi: 10.1101/cshperspect.a017616

Cite this article as Cold Spring Harb Perspect Biol 2015;7:a017616 
Q. Helleu et al.

preferential transmission that results directly or indirectly from an event that took place before, during, or after meiosis. Sex chromosome drive is different from sex-ratio adjustment, in which the favored chromosome is not the actor of its drive (West and Sheldon 2002). As emphasized by Sandler and Novitski (1957), it is also different from selection in the haploid phase as a consequence of the gamete's intrinsic fitness.

Only a few dozen cases of sex chromosome drive have been described, mainly in Drosophila and other Diptera (reviewed in Jaenike 2001; Burt and Trivers 2006). One possible explanation for the rarity of reported cases is that a biased sex ratio is not evolutionarily stable. Fisher (1930) predicted that natural selection will favor a 1:1 sex ratio, and that any deviation will be counterselected. This means that variants with counteracting effects can be selected at unlinked loci. Consistent with this prediction, autosomal drive suppressors and resistant $\mathrm{Y}$ chromosomes have been found in several Drosophila species (De Carvalho and Klaczko, 1994; Carvalho et al. 1997; Cazemajor et al. 1997). Three different cryptic X-linked $S R$ systems have been described in the same species (Drosophila simulans: Paris, Winters, and Durham systems), showing that they can evolve repeatedly and be completely neutralized in the wild, remaining undetectable unless appropriate genetic crosses are performed (Merçot et al. 1995; Tao et al. 2001, 2007a). D. simulans also teaches us that the time window leading up to neutralization can be very narrow (Bastide et al. 2013). However, variants that enhance distortion can be selected if they are linked to the distorter. Inversions should prevent recombination with nondriving $\mathrm{X}$ chromosomes and keep together the loci that interact to induce drive, as found in D. pseudoobscura (Wu and Beckenbach 1983). These examples illustrate the extended genetic conflict that can result from the evolution of sex chromosome drive.

Among the known cases of sex chromosome drive, $\mathrm{X}$ chromosome drive is much more common than Y chromosome drive. This may be because Y-linked drivers are always expressed, at each generation, unlike X-linked drivers. All else being equal, Y chromosome drive spreads faster and leads to a higher risk of extinction owing to the lack of females (Hamilton 1967). Furthermore, when the sex chromosomes are well differentiated, the Y chromosome usually has many fewer genes, which may provide fewer opportunities for a driver to evolve. On the other hand, heteromorphic sex chromosomes are expected to facilitate the evolution of meiotic drive. Indeed, the more divergent the sex chromosomes are, the less they recombine, reducing the risk of producing a suicide chromosome that carries both the driver and a sensitive allele at the target locus (Charlesworth and Hartl 1978; Frank 1991; Hurst and Pomiankowski 1991).

\section{OCCURRENCE AND MECHANISMS OF SEX CHROMOSOME DRIVE}

Nearly all of the well-established cases of sex chromosome drive occur in the distant Diptera and Rodentia taxa (reviewed in Jaenike 2001; Burt and Trivers 2006). Naturally occurring $\mathrm{X}$-linked drivers have been reported in 13 Drosophila species with sporadic taxonomic distribution across the genus. A similar phenotype has been described in four species of stalkeyed flies and in the tsetse fly. Y drive is much less common, but is known in two mosquito species: Aedes aegyptii and Culex pipiens.

Whereas the dipteran drivers usually operate during meiosis (Fig. 1), the sex chromosome drivers known in rodents first change the sex of their carriers (but see Cocquet et al. 2012). XY females have been described in lemmings, in voles, and in the African pygmy mouse-all associated with the presence of feminizing X chromosomes that lead to female-biased population sex ratios (Fredga et al. 1976; Gileva 1987; Bianchi 2002; Veyrunes et al. 2010).

Unbalanced sex ratios are common in angiosperms with separate sexes. However, this is probably more often because of pollen competition between lower quality Y-bearing pollen and higher-quality X-bearing pollen (but see Taylor and Ingvarsson 2003). Adaptive adjustment of offspring sex ratio occurs in some birds, and some placental and marsupial mammals, but there is no definite evidence so far of a causal 


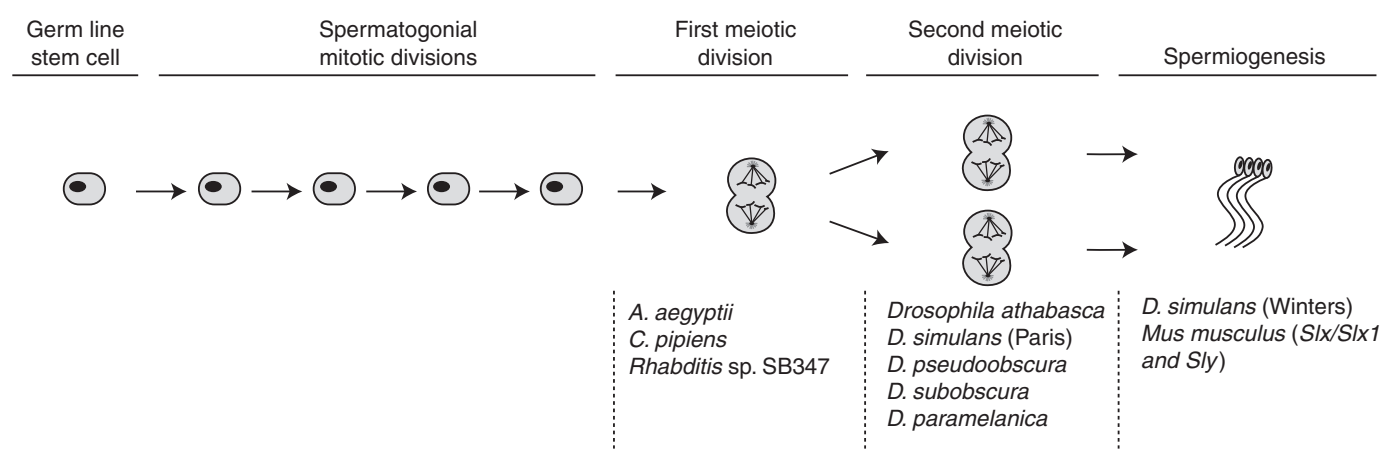

Figure 1. Spermatogenesis stages at which cellular phenotypes of sex chromosome drive are observed.

mechanism during gametogenesis (West and Sheldon 2002; Rutkowska and Badyaev 2008; Navara 2013). In contrast, strong female-biased progeny produced by males of the nematode Rhabditis sp. SB347 has recently been ascribed to differential transmission of X-bearing sperm. In this species with $\mathrm{X} 0$ males, the trait seems related to premature splitting of the $\mathrm{X}$ chromosome into sister chromatids during meiosis I. The cellular components that are essential for sperm motility are then partitioned almost exclusively to the X-bearing sperm (Shakes et al. 2011). Below, we summarize what is currently known about the mechanism of sex chromosome drive in rodents, Drosophila, and other dipterans. In Drosophila, we also focus on recent data and hypotheses about the molecular basis of drive.

\section{Rodentia}

Several species of rodents show $\mathrm{X}$ chromosome variants (usually referred to as $\mathrm{X}^{*}$ ) that cause $\mathrm{XY}$ individuals to develop into females. The most extreme case of $\mathrm{X}$ chromosome drive operating by feminization of XY individuals is known in the wood lemming Myopus schisticolor: $\mathrm{X}^{*} \mathrm{Y}$ females produce only $\mathrm{X}^{*}$ eggs, owing to the nondisjunction of the sister chromatids of both sex chromosomes during some mitotic divisions in the germline. The $\mathrm{X}^{*} \mathrm{X}^{*}$ cells enter meiosis, but the YY cells are unviable. As a result, the $\mathrm{X}^{*}$ chromosome is transmitted to $100 \%$ of the progeny-all are therefore female. In the lemming Dicrostonyx torquatus, $\mathrm{X}^{*} \mathrm{Y}$ females produce both $\mathrm{X}^{*}$ - and Y-bearing gametes. The primary drive strength is lower in this case, as the preferential transmission of the $\mathrm{X}^{*}$ chromosome does not occur at the gamete stage. The sex bias occurs after fertilization; YY zygotes die, allowing the $\mathrm{X}^{*}$ chromosome to be passed on to two-thirds of the progeny $\left(\mathrm{X}^{*} \mathrm{X}\right.$ and $\mathrm{X}^{*} \mathrm{Y}$ females). XY females have also been found, sometimes at high frequencies, in the African pygmy mouse Mus minutoides (Veyrunes et al. 2010; Saunders et al. 2014) and in eight different species of Akodon (reviewed in Bianchi 2002). In all four of these genera, the driving $X$ also benefits from better reproductive performance of XY females compared with XX females. For example, in Akodon azarae, $\mathrm{XY}$ females have a longer reproductive life span than XX females, and they have the same litter size even though the YY embryos are not viable (Hoekstra and Hoekstra 2001). The XY female embryos also have an accelerated rate of preimplantation development (Espinosa and Vitullo 2001).

The genetic bases of these sex-reversal mechanisms are unknown. Their recurrent evolution is likely related to the peculiar structure of the Sry gene in Muroidea. It contains an unstable microsatellite encoding a glutamine-rich domain of variable length. This domain functions as a genetic capacitor that could foster the accumulation of intragenic cryptic variation and promote the evolution of male sex determination systems that are not Sry dependent (Chen et al. 2013). The association with an Xlinked deletion has been proven in Myopus, and $\mathrm{X}$ linkage is strongly suspected in Dycrostonyx 
Q. Helleu et al.

and Akodon species where driving $\mathrm{X}$ chromosomes show specific rearrangements (Fredga and Bulmer 1988; Ortiz et al. 2009).

Besides these cases associated with sex reversal, experimental studies on the mouse revealed that sex chromosome drive in rodents can also occur in a very different way. Males with a deletion that removes two-thirds of the Y chromosome long arm produce female-biased progeny. This is because of an impaired fertilizing ability of Y-bearing sperm (Ward and Burgoyne 2006). The deletion causes imbalance in copy number of antagonistic X-linked (Slx/Slx1) and Ylinked $(S l y)$ genes involved in the epigenetic control of postmeiotic sex chromatin (PMSC) expression (Cocquet et al. 2012). There is evidence to support the idea that a long-lasting conflict exists between these antagonistic genes in rodents (see the section Evolutionary Consequences).

\section{Drosophila}

In Drosophila, X drive can be very strong, sometimes leading to $100 \%$ female progeny, or close to it. $\mathrm{X}$ drive in Drosophila is often associated with abnormal behavior of the Y chromosome during meiosis II, which can lead to segregation failure of the Y chromosome's sister chromatids (direct observation in D. simulans Paris, D. pseudoobscura, and D. athabasca; inference in Drosophila subobscura and Drosophila paramelanica [Fig. 1]; reviewed in Cazemajor et al. 2000; Jaenike 2001). All of the cytological studies in Drosophila and stalk-eyed flies show evidence of spermiogenesis failure, which is thought to affect the spermatids containing the target chromosome, as shown in D. simulans Paris (Cazemajor et al. 2000).

Although X drive has been known for a long time, only one driver gene, Dox (Distorter on the $X$ ) has been identified molecularly. Its function is unknown. Found in D. simulans, Dox is suppressed and cryptic in its natural context. It was revealed by interspecific crosses that lifted the suppression. Dox is a recent gene that arose from another recent gene, Mother of Dox (MDox) (Tao et al. 2007a,b). Dox and MDox appear to be transcribed as RNAs that are noncoding or that have a very limited coding potential. Dox does not seem to cause meiotic defects, but rather postmeiotic failure of nuclear condensation in the Y-bearing sperm (Tao et al. 2007b; Yasuno et al. 2013). Remarkably, Dox gave rise through retrotransposition to an autosomal suppressor, Not much yang (Nmy). An RNA interference mechanism seems to be involved in the suppression of Dox by Nmy.

The Paris sex-ratio drive, also found in D. simulans, has the best-described cellular phenotype, but the driver elements and the suppressors are still unknown. Nevertheless, two drive loci have been mapped on the $\mathrm{X}$ chromosome, about $150 \mathrm{~kb}$ away from each other, both required to generate the distortion (Montchamp-Moreau et al. 2006). The first locus corresponds to a segmental duplication containing six genes, all expressed in the testes (Fouvry et al. 2011). The second locus is the HP1D2 gene (GD16106), a member of the heterochromatin protein 1 (HP1) gene family (Q Helleu et al., unpubl.).

\section{Mosquitoes}

In $A$. aegypti and C. pipiens, Y drive can also result in high sex-ratio biases (Wood and Newton 1991). In both species, Y drive is associated with breakage of the $\mathrm{X}$ chromosome (and of the $\mathrm{Y}$ and autosomes to a much lesser extent) at some stage before anaphase I. This breakage may be caused by failed crossover (Newton et al. 1976). A high proportion of sperm heads in $A$. aegypti driving males contains a remarkable large amount of DNA, which likely results from incomplete anaphase during the first and second meiotic divisions (Newton et al. 1978).

In both species, the sex chromosome driver is tightly linked to the sex-determining locus on the nondegenerated Y chromosome. The sex chromosome driver in A. aegypti has been better studied, and several modifiers have been genetically mapped-two suppressors and an enhancer (Wood and Ouda 1987; Wood and Newton 1991). Shin et al. (2011) used comparative transcriptomics to characterize the sex chromosome drive testes transcription profile, and identified genes associated with signal trans- 
duction and cell cycle. Among these they found some Ras-related genes.

Heterochromatin, Small RNAs, and Genetic Conflict

Most of the cellular phenotypes described above - at least, those described in Drosophila species - suggest a failure in the chromatin state regulation. In yeast and Drosophila, defects in heterochromatin formation can lead to chromosome missegregation (Allshire et al. 1995; Kellum and Alberts 1995). Moreover, the interaction between the heterochromatin and the proteins involved in its regulation is one of the key steps that led to the centromere drive hypothesis, as argued by Malik and Henikoff (2009). The interesting feature about SR in Drosophila is that nearly all the Y chromosomes in this genus are ancient and highly heterochromatic (Bachtrog 2013). We suggest that for meiotic drive, the X chromosome-via DNA-binding proteins or other proteins involved in the regulation of the chromatin state-can take advantage of the singular heterochromatin state of the Y chromosome and lead to its missegregation.

The HP1 gene family is involved in heterochromatin regulation and formation (Cheutin et al. 2003; Olszak et al. 2011). The phylogenomic analysis in Drosophila, performed by Levine et al. (2012), has revealed a great potential for many members of this family to be involved in episodic genetic conflicts, like the germline-restricted Oxpecker. Some HP1s genes could suppress the selfish activity of genomic parasites, including meiotic drivers. Once suppressed, the selfish element can degenerate, then its suppressor. That could explain HP1 turnover and neofunctionalization, shown, for instance, for Umbrea (Levine and Malik 2013; Ross et al. 2013). The discovery that HP1D2 in D. simulans is one of the distorters in the Paris system is highly significant in this respect. This is the first evidence of an HP1 protein directly involved in an ongoing genetic conflict.

Another potential actor of drive is the small RNA library that guides the DNA-binding proteins. Small RNAs are involved in the regulation of the chromatin state, in interaction with HP1s (Pal-Bhadra et al. 2004; Brower-Toland et al. 2007; Gu and Elgin 2013). Produced by satellite DNA, transposable elements, and genomic tandem repeats, small RNAs can induce heterochromatin perturbation, altering DNA condensation or segregation (Allshire et al. 1995; Grewal et al. 1998; Aravin et al. 2001; Lippman et al. 2004). Recent data support the view that small RNA can be involved in regulation of meiotic drivers. Indeed, piRNA pathway mutants enhance the drive caused by segregation distorter in Drosophila melanogaster (Gell and Reenan 2013). In addition, the $S R$ driver Winters in D. simulans is thought to be suppressed through small RNA-based silencing (Tao et al. 2007b). This is also true for Stellate repeated genes, which lead to male sterility in the absence of a suppressor (Livak 1990). This shows that the emergence of homologous repeated sequences can resolve a conflict (Aravin et al. 2001; Stapleton et al. 2001).

\section{POPULATION DYNAMICS OF SEX CHROMOSOME DRIVE: THE Drosophila MODEL}

The fate of a sex-linked driver that emerges in a population can be diverse, causing population extinction, staying at a stable polymorphism, or triggering the evolution of (and possibly cycling with) suppressors of drive. Many documented examples come from the genus Drosophila (Fig. 2).

\section{Population Extinction}

In theory, even a low transmission advantage should allow a driver to quickly invade a population. Without any countervailing effect, the presence of a strong driver on a sex chromosome can lead to unisexual populations that will collapse (Sturtevant and Dobzhansky 1936; Hamilton 1967). If extinction can be observed (although rarely) in the laboratory (Lyttle 1977; Price et al. 2010a), it should strongly depend on life-history parameters and stochastic effects such as demographic ones (Jaenike 1996; Hatcher et al. 1999; Taylor and Jaenike 2002, 2003). 
Q. Helleu et al.

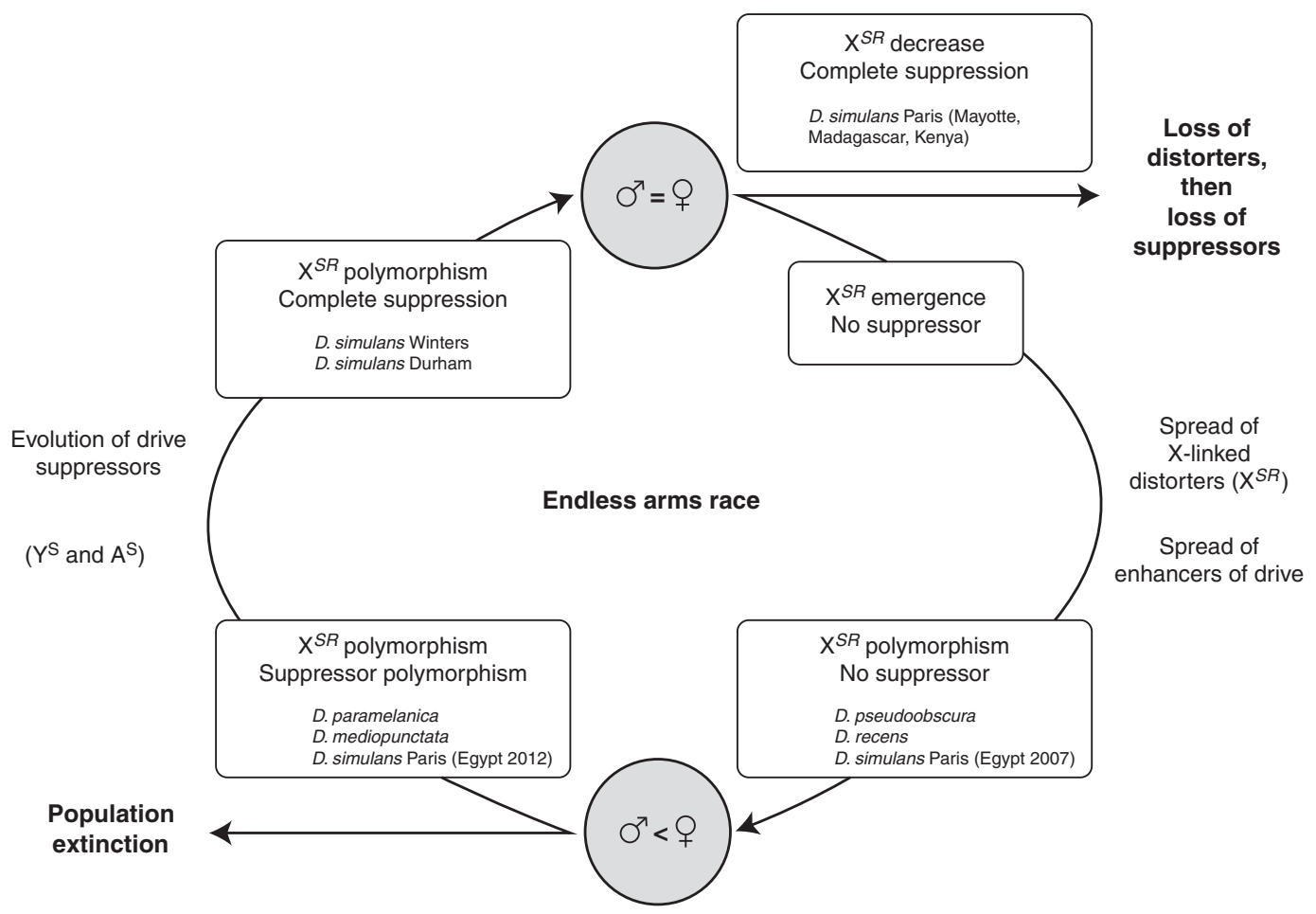

Figure 2. Model for the evolution of X-chromosome drive, with examples from Drosophila. The evolution can cease by population extinction or the system can stay at a stable polymorphism (without suppressors [e.g., in D. pseudoobscura] or with suppressors [e.g., in Drosophila mediopunctata]). The only driver found to cycle in natural populations is the young Paris system of $D$. simulans: the driver is currently disappearing in the Indian Ocean (Madagascar, Mayotte) where complete suppression has evolved (Bastide et al. 2011) but is increasing in frequency along with suppressors in the Middle East (e.g., in Egypt) (Bastide et al. 2013).

In fact, extinction driven by sex chromosome drive has never been observed in natural populations. Only recently, a population crash may have been related to a high $S R$ frequency in Drosophila neotestacea (Pinzone and Dyer 2013). The absence of examples might be because, at least in part, of the short period of time during which the phenomenon can be observed. The frequency of extinctions induced by $S R$ drive is probably not negligible (Carvalho and Vaz 1999; Jaenike 2001). There are few known cases of sex chromosome drive systems that are still evolving (such as the Paris system of $D$. simulans), and the vast majority of drivers that have been described so far are either cryptic (i.e., fixed and suppressed in the populations, such as the Winters system of $D$. simulans) or in a stable polymorphism (such as D. pseudoobscu$r a$ 's $S R$ ). Now that we can more precisely date the origin of such elements using molecular population genetics tools, it appears that most of them are old (see below).

If the extinction effect is strong enough, it should be possible to use such selfish elements for pest management through population replacement (Hastings 1994; Sinkins and Gould 2006). For example, it might be feasible to use a killer $\mathrm{Y}$ for this purpose in the mosquito $A$. aegypti (Craig et al. 1960). A driving Y would be more efficient than a driving $\mathrm{X}$, because it would drive in every individual carrying it, whereas the $\mathrm{X}$ would not drive in females (Hamilton 1967; Burt and Trivers 2006). However, naturally occurring drivers will not work if there are resistances in target populations (Wood and Newton 1991). Alternatively, it is theoretically plausible to invade a pest population with engineered sex chromosome drivers 
(e.g., Deredec et al. 2011) as it has been performed in experimental populations of D. melanogaster (e.g., Akbari et al. 2013).

\section{Maintenance of Polymorphism}

Several $S R$ drivers that have been detected in natural populations show stable polymorphism. The ancient SR from D. pseudoobscura-one of the first to be discovered (Sturtevant and Dobzhansky 1936)—might be approximately one million years old (Babcock and Anderson 1996; Kovacevic and Schaeffer 2000). It has remained at the same frequencies for more than 50 years in Arizona (Beckenbach 1996). Much theoretical and empirical work has been devoted to explaining how the $S R$ polymorphism is maintained in this species, given that there is no evidence of either resistance or suppression (Policansky and Ellison 1970; Beckenbach et al. 1982). Following the experimental work by Wallace (1948), a model was developed in which the selection coefficient associated with each genotype is constant, and the transmission advantage of $S R$ is compensated by deleterious effects in females (Edwards 1961; Curtsinger and Feldman 1980). But considering that the driver is acting during male gametogenesis, it is unlikely that it lowers female fitness by itself. This would instead be a result of other loci that are tightly linked to $S R$ or that reside within chromosome rearrangements; several drivers, including D. pseudoobscura $S R$, are associated with inversions (Jaenike 2001). In Drosophila recens, the driver seems to be disappearing because of the accumulation of deleterious mutations within large $\mathrm{X}$ chromosome inversions associated with the driver (Dyer et al. 2007).

Alternatively, polymorphism can be maintained through frequency-dependent processes; $S R$ males usually suffer from reduced sperm production to at least half of that of standard males (e.g., in Drosophila, Cyrtodiopsis, or Aedes) (Hickey and Craig 1966; Policansky and Ellison 1970; Hauschteck-Jungen and Maurer 1976; Wu 1983b; Montchamp-Moreau and Joly 1997; Presgraves et al. 1997). If the realized fecundity (i.e., number of offspring sired) is a sigmoidal function of the number of gametes produced, then $S R$ polymorphism can be maintained by frequency-dependent selection (Hartl 1972; Jaenike 1996). When the proportion of females increases in the population because of the driver, the male mating rate increases and standard males are favored because they sire proportionally more offspring relative to their transferred sperm. Variation in population density can influence the male mating rate and contribute to the differences in $S R$ abundance (Beckenbach 1978; Atlan et al. 2004). This could explain the seasonal fluctuations of $S R$ as do the seasonal fluctuations of $S R$ that are observed in D. pseudoobscura (Bryant et al. 1982). The negative effect of multiple mating on the fertility of $S R$ males has been well documented in laboratory conditions (e.g., Hickey and Craig 1966; Wu 1983c; Jaenike 1996; Atlan et al. 2004; Wilkinson et al. 2006), and the effect of density on $S R$ frequency has been observed in experimental populations of D. pseudoobscura (Beckenbach 1983). In addition, as for many other selfish genetic elements (Price and Wedell 2008), SR males are usually poor sperm (or pollen) competitors against standard males (e.g., Wu 1983b; Taylor et al. 1999; Wilkinson and Sanchez 2001; Wilkinson et al. 2006; Angelard et al. 2008; Price et al. 2008b). Therefore, a high female mating rate may help stabilize the $S R$ polymorphism. Reduced sperm production in $S R$ males could increase the female propensity to remate (Beckenbach 1981; Atlan et al. 2004), and standard males could suppress female remating in the presence of even a low number of $S R$ males (Price et al. 2010b). However, when the driver increases in frequency in the population and the sex ratio becomes highly female biased, the female mating rate will tend to decrease, reducing sperm competition and therefore the $S R$ disadvantage. Taylor and Jaenike (2002) modeled the dynamics of an X-linked driver under sperm competition and showed that opposing effects of male and female mating rates can lead to a stable equilibrium in certain conditions. When the $S R$ male disadvantage is not too high, the driver frequency can even stabilize at $\sim 0.5$.

Population structure could influence driver distribution at the metapopulation level (Price 
Q. Helleu et al.

et al. 2010a). For example, local populations that would be more sensitive to $S R$ invasion would go extinct more rapidly but send out fewer migrants, increasing the probability of the driver persisting (Van Boven and Weissing 1999). Moderate gene flow between demes can greatly favor the stability of the polymorphism (Taylor and Jaenike 2003). When a stable polymorphism is observed at the metapopulation level, there are likely local dynamics behind it (Hatcher 2000). Environmental factors such as climate have long been invoked as a determinant of $S R$ distribution (e.g., in D. pseudoobscura) because several drivers show latitudinal clines in frequency (Sturtevant and Dobzhansky 1936). Temperature-related fertility differences do not seem to impact the distribution of $D$. pseudoobscura SR (Price et al. 2012), although this could explain the high correlation between climate variables and $S R$ frequency in $D$. neotestacea (Dyer 2012). Moreover, the mechanisms by which ecological variables could influence the maintenance of polymorphism is difficult to determine and may be indirect.

\section{Evolution of Suppressors}

Sex chromosome drivers are thought to trigger the evolution of resistant Y chromosomes (for X-linked drivers) and/or autosomal suppressors. When a population becomes highly female biased, any variant that produces more males will be favored through a frequency-dependent selective process to rebalance the sex ratio (Fisher 1930; Bull and Charnov 1988). Y-linked resistance should rapidly spread to fixation, especially if it is not associated with deleterious fitness effects (Thomson and Feldman 1975; Clark 1987), or it should cycle with the driving X (Hall 2004). Alternatively, it can reach a stable equilibrium that depends on frequency-dependent interactions between the driving $\mathrm{X}$ and the resistant Y (Carvalho et al. 1997). Autosomal suppressors of drive are also predicted to be favored and increase in frequency (Hamilton 1967), except when the driver is very strongly deleterious (Wu 1983a; Vaz and Carvalho 2004). Driver-suppressor frequencies can attain equilibrium when there is overdominance in females (Wu 1983a) or when the driver is partially deleterious (Vaz and Carvalho 2004). In the latter model, autosomal suppressors go to fixation only if the driver has no effect on fitness (Vaz and Carvalho 2004). The same qualitative prediction can be made for a resistant $\mathrm{Y}$ chromosome, but its fixation probability is higher, even with a deleterious SR (Carvalho and Vaz 1999). Indeed, Y-linked resistance should be more strongly selected than autosomal suppression (Jaenike 2001; Atlan et al. 2003). In addition to the fitness cost associated with drive and suppression in males and females (heterozygous or homozygous for $S R$ ), the fate of the driver and suppressor can also depend on the population structure or the time at which the suppressor arises during the spread of the driver (Carvalho and Vaz 1999; Hall 2004; Vaz and Carvalho 2004).

After the suppressor has fixed (or nearly fixed) in a population, the driver can either evolve neutrally or, if it is deleterious, decline in frequency (Burt and Trivers 2006). Neutral evolution would produce cryptic drive systems that may be revealed by chance, like the $D$. simulans Winters (Tao et al. 2007a,b; Kingan et al. 2010), whereas selection against a deleterious driver can generate evolutionary cycles of drive and suppression (Hall 2004). Resistant Y and autosomal suppression have been detected in many Drosophila species that show SR drive (e.g., Stalker 1961; Voelker 1972; De Carvalho and Klaczko 1993; Carvalho et al. 1997; Cazemajor et al. 1997; Jaenike 1999; MontchampMoreau et al. 2001), making the evolution of suppression more the rule than the exception in this genus. Nevertheless, the dynamics of drive and suppression has rarely been assessed in natural populations, given the paucity of known young and still-evolving systems. In $D$. mediopunctata, SR frequency has not changed over 10 years, suggesting that the driver has been balanced at an equilibrium frequency by partial suppression and natural selection (Carvalho and Vaz 1999). The only known example of coevolution between drive and suppression in natural populations has been observed with the $D$. simulans Paris $S R$ system. The driver has been declining in East African populations (Mayotte, 
Madagascar, Kenya) in which there is complete suppression (Bastide et al. 2011), but it has risen along with suppression in the Middle East within a few years, especially in Egypt (Bastide et al. 2013). In the Middle Eastern populations, suppression seems to be increasing much more quickly in one population than in the other, possibly reflecting Y-linked resistance as opposed to autosomal suppression dynamics. In both species, the increase in suppression in response to $S R$ fixation had been shown in experimental populations (Carvalho et al. 1998; Capillon and Atlan 1999).

\section{EVOLUTIONARY CONSEQUENCES}

\section{Mating System Evolution}

Sex chromosome drive can have a number of consequences on the evolution of sexual reproduction processes, usually resulting from adaptations to counteract drive (Presgraves 2008) through sexual selection and sexual conflicts. In $D$. pseudoobscura, for example, $S R$ promotes polyandry in experimental populations and may have evolved to prevent population extinction (Price et al. 2008a, 2010a). Accordingly, SR prevalence is negatively correlated with polyandry in natural populations of this species (Price et al. 2014). Selfish genetic elements in general can be common drivers of the evolution of polyandry (reviewed in Wedell 2013), and this has been suggested in other SR systems (e.g., Wilkinson et al. 2003; Angelard et al. 2008; but see discussion in Pinzone and Dyer 2013). In addition, if polyandry may evolve through sexual selection in females, sperm competition theory predicts that males should benefit from a reduction in female mating rate to increase their mating success (Parker 2006). Results from experimental populations of D. pseudoobscura tend to support this prediction for non-SR males (Price et al. 2010b). Driving sex chromosomes can also trigger the evolution of mate choice. In the stalk-eyed fly Cyrtodiopsis dalmanni, males show a dimorphism in eye-stalk span that is genetically linked with drive and suppression, and females have evolved preferences for long eye stalks in the presence of $S R$ (Wilkinson et al.
1998; Cotton et al. 2014). This process appears to be rare (Price et al. 2012) and requires the suppression of recombination between meiotic drive and the male sexual character loci (Lande and Wilkinson 1999).

\section{Sex Determination, Sex Chromosome, and Genome Evolution}

Sex chromosome drivers can have consequences on the linked polymorphism, usually reducing it through (recurrent) selective sweeps (e.g., Chevin et al. 2009; Kingan et al. 2010; Dyer et al. 2013), and especially when they tend to recruit inversions (e.g., Dyer et al. 2007). However, the functional consequences of this phenomenon is not well known.

There is a great deal of speculation about the role that sex chromosome drive plays in the evolution of sex-determining mechanisms. As seen in rodents, mutations that change the sex-determining system must be costly-in particular, in species with heteromorphic chromosomes. Segregation distortion can very efficiently promote a disadvantageous mutation. For example, Charlesworth and Dempsey (2001) proposed that the X0/XY system of Microtus oregoni has evolved in such a way. They assumed that a single X-linked mutation causes the observed mitotic nondisjunction of $\mathrm{X}$ chromosomes in the male germline (which produces only 0 and $\mathrm{Y}$ sperm). They showed that the mutant $\mathrm{X}$ can spread only if it benefits from complete transmission advantage in females, as this counterbalances the transmission failure in the males. However, as far as we know, there is still no definite evidence of species with a fixed switch caused by the spread of a driving chromosome.

Alternatively, there may be changes in the sex-determining mechanism through the evolution of new feminizing or masculinizing genes to suppress the sex-ratio bias induced by a sexlinked driver. Kozielska et al. (2009) have modeled these scenarios in the case of XY sex determination. In particular, they may account for the evolution of masculinizer genes in Diptera (reviewed in Burt and Trivers 2006). Interestingly, Kozielska et al. (2009) point out that the driver element, which is assumed to reduce in- 
Q. Helleu et al.

dividual fitness, is often lost and no longer detectable once the new sex-determining system has become established.

The phenomenon of centromere drive that can occur in females (i.e., the preferential transmission in eggs) is thought to drive karyotype evolution (de Villena and Sapienza 2001). This specific conflict may also contribute to fixation of neo-sex chromosomes that arise from the fusion between an autosome and a sex chromosome. This was postulated by Yoshida and Kitano (2012), who found that neo-X chromosomes were more prevalent among mammalian species that have a higher percentage of metacentric chromosomes.

In a wide range of taxa (mammals, nematodes, birds), the sex chromosomes are transcriptionally silenced by epigenetic marks during meiosis (Turner 2007; Namekawa and Lee 2009). This meiotic sex chromosome inactivation (MSCI) is thought to have first evolved as a defense mechanism against selfish elements, including meiotic drivers (Meiklejohn and Tao 2010). Recent advances in the understanding of epigenetic control of postmeiotic sex chromatin (PMSC) expression in Mus musculus provides strong support for the idea that the protagonists of the genetic conflict over sex chromosome transmission can more broadly drive the evolution of gene expression, genome structure, and ultimately lead to speciation. In the male germline of $M$. musculus, many sexchromosome-linked genes important for sperm differentiation and function are reactivated after meiosis (Mueller et al. 2008), but their expression remains tightly regulated by repressive epigenetic marks inherited from MSCI, via the action of Sly, an essential Y-linked multicopy gene. Males deficient in Sly show up-regulation of these genes, suffer fertility defects, and produce offspring with a sex ratio that is moderately biased toward females, because of different fertilizing ability of $\mathrm{X}$ - and Y-bearing sperm (Ward and Burgoyne 2006). Interestingly, the $\mathrm{X}$-linked multicopy genes $S l x / S l x 1$, related to Sly, are among the up-regulated genes. Cocquet et al. (2012) have showed that the products of Sly and Slx/Slx 1 genes have antagonistic effects on the epigenetic marks associated with PMSC, on the expression of sex-chromosome-linked genes, and consistently on offspring sex ratio. Imbalance of Sly and Slx/Slxl copy numbers causes sex-ratio distortion, sperm differentiation defects, and male infertility, but $S l x / s l x 1$ deficiency rescues the defects caused by Sly deficiency and vice versa. The authors thus propose that the conflict between Sly and Slx/Slx 1 genes led to their massive amplification on the $\mathrm{Y}$ and $\mathrm{X}$ chromosomes, respectively, during rodent evolution (Fig. 3A) and also to the amplification of spermiogenic genes throughout the genome to escape the repressive effect of Sly. Finally, they argue that copy number imbalance may be one contributor to the evolution of hybrid sterility in mice (Fig. 3B).

\section{Speciation}

The hypothesis that meiotic drivers play a role in speciation has long been controversial. Frank (1991) and Hurst and Pomiankowski (1991) independently claimed that Haldane's rule (the preferential sterility or inviability of the heterogametic $\mathrm{F}_{1}$ hybrid) could be explained by the divergent evolution of sex chromosome drivers and their suppressors. Coyne et al. (1991) and Charlesworth et al. (1993) contested this hypothesis, mostly because of the lack of empirical evidence (Johnson and Wu 1992; Coyne et al. 1993). At the time, the support came from observations in D. subobscura, where an $\mathrm{X}$ chromosome causing drive in the local genetic background caused male sterility when it was combined with autosomes from another population (Hauschteck-Jungen 1990). Since then, examples of a link between sex chromosome drive and hybrid male sterility have accumulated.

Tao et al. (2001) found an X-linked cryptic meiotic driver in D. simulans that was unleashed by the introgression of Drosophila mauritiana alleles at the autosomal locus Too much yin (Tmy). The introgression causes both sex chromosome drive and male sterility in $D$. simulans males. Both traits localize to a DNA fragment of $80 \mathrm{~kb}$ or smaller and may be pleiotropic effects from a single gene. Similarly, Yang et al. (2004) characterized a cryptic X-linked meiotic driver 
A

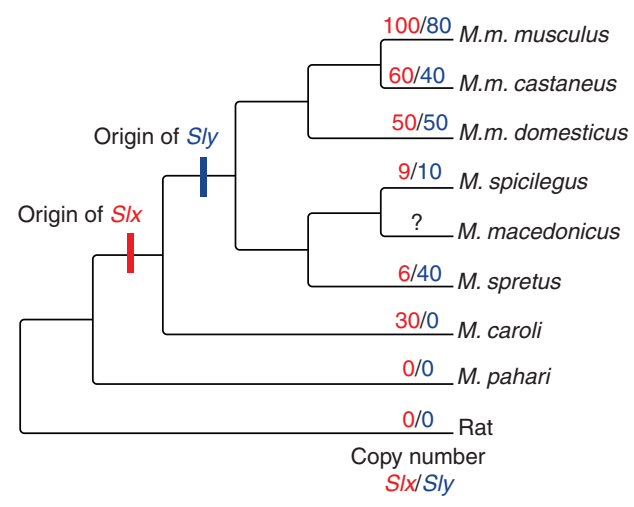

B

M.m. musculus female x M.m. domesticus male

Sterile $F_{1}$ male

(overexpression of reproductive genes)

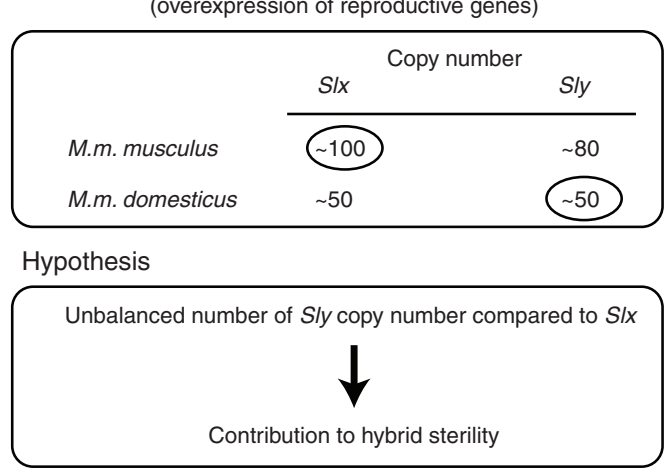

Figure 3. (A) Evolution of Slx/Sly copy number in some lineages of the genus Mus. (Reprinted from Good 2012 under the terms of the Creative Commons Attribution License, which permits unrestricted use, distribution, and reproduction in any medium.) (B) Deficiency in the number of Sly copies compared to Slx copies could contribute to $\mathrm{F}_{1}$ male hybrid sterility in crosses between M.m. musculus females and M.m. domesticus males (Published courtesy of Julie Cocquet.)

on the neo-X chromosome of Drosophila albomicans expressed in $\mathrm{F}_{1}$ male hybrids between D. albomicans and Drosophila nasuta.

Later, Phadnis and Orr (2009) identified an X-linked gene, Overdrive ( $O v d$ ), that causes both segregation distortion and sterility in hybrid males between the two subspecies Drosophila pseudoobscura pseudoobscura and Drosophila pseudoobscura bogotana. Ovd is predicted to encode a polypeptide with a DNA-binding domain that targets trinucleotide repeats. The hybrids become weakly fertile when they are old, and the Ovd allele from D.p. bogotana in the hybrid $F_{1}$ males leads to a sex-ratio bias, as the $\mathrm{F}_{1}$ males sire more than $90 \%$ daughters.

Because the spread of a strong X-linked driver can lead to the evolution of Y-resistant chromosome, Hurst and Pomiankowski (1991) also proposed that the newly selected $\mathrm{Y}$ could be incompatible with some recently derived genomes. The Y chromosome can contribute to hybrid sterility, sometimes through an interaction with the rest of the genome (Johnson et al. 1993; Lamnissou et al. 1996; Campbell et al. 2012). Recent studies have started to shed light on the nature of these interactions (Chippindale and Rice 2001; Lemos et al. 2008; Sackton et al.
2011; Zhou et al. 2012; Branco et al. 2013). Despite the fact that there is no evidence of a resistant $Y$ chromosome involved in a postzygotic barrier, the hypothesis remains relevant (McDermott and Noor 2010).

Sex chromosome drive can likely also lead to speciation through a change in sex-determining mechanism. This could be the case for rodents' feminizing $\mathrm{X}$ chromosomes and the insects Sciara coprophila, Musca domestica, and Neococcoidea (Haig 1993a,b; Kozielska et al. 2009).

\section{CONCLUDING REMARKS}

Like other selfish genetic elements, sex-linked meiotic drivers usually trigger genome adaptations to resolve the conflict that they induce. This can be achieved through neofunctionalization or subfunctionalization of duplicated genes (Gallach and Betrán 2011; Ross et al. 2013). For example, each cluster of the abovementioned repeated genes $S x l / S x l 1$ and Sly is needed when the other is present. But when both are removed, fertility is restored, suggesting that they have been amplified and conserved only because of the genetic conflict that they initiated and/or resolved. By such processes, 
Q. Helleu et al.

genetic conflicts should contribute to increased genome size and complexity and be a major driver of genome evolution. Recent work on emblematic cases of genetic incompatibilities pinpoint a twofold challenge: identifying multiple genes with complex epistatic interactions and understanding the role of heterochromatic noncoding DNA repeats in sex-chromosomeassociated genetic conflicts.

\section{ACKNOWLEDGMENTS}

We thank William Rice and Sergey Gavrilets for the invitation to contribute to this volume and Julie Cocquet and Frédéric Veyrunes for helpful comments. This work is supported by the Centre National de la Recherche Scientifique (UPR 9034) and a grant from the Agence Nationale de la Recherche (ANR-12-BSV7-001401). Q.H. is funded by a French ministerial scholarship.

\section{REFERENCES}

Akbari OS, Matzen KD, Marshall JM, Huang H, Ward CM, Hay BA. 2013. A synthetic gene drive system for local, reversible modification and suppression of insect populations. Curr Biol 23: 671-677.

Allshire RC, Nimmo ER, Ekwall K, Javerzat JP, Cranston G. 1995. Mutations derepressing silent centromeric domains in fission yeast disrupt chromosome segregation. Genes Dev 9: 218-233.

Angelard C, Montchamp-Moreau C, Joly D. 2008. Femaledriven mechanisms, ejaculate size and quality contribute to the lower fertility of sex-ratio distorter males in Drosophila simulans. BMC Evol Biol 8: 326.

Aravin AA, Naumova NM, Tulin AV, Vagin VV, Rozovsky YM, Gvozdev VA. 2001. Double-stranded RNA-mediated silencing of genomic tandem repeats and transposable elements in the D. melanogaster germline. Curr Biol 11: 1017-1027.

Atlan A, Capillon C, Derome N, Couvet D, MontchampMoreau C. 2003. The evolution of autosomal suppressors of sex-ratio drive in Drosophila simulans. Genetica 117: $47-58$.

Atlan A, Joly D, Capillon C, Montchamp-Moreau C. 2004. Sex-ratio distorter of Drosophila simulans reduces male productivity and sperm competition ability. J Evol Biol 17: $744-751$.

Babcock CS, Anderson WW. 1996. Molecular evolution of the Sex-Ratio inversion complex in Drosophila pseudoobscura: Analysis of the Esterase-5 gene region. Mol Biol Evol 13: 297-308.

Bachtrog D. 2013. Y-chromosome evolution: Emerging insights into processes of Y-chromosome degeneration. Nature Rev Genet 14: 113-124.
Bastide H, Cazemajor M, Ogereau D, Derome N, Hospital F, Montchamp-Moreau C. 2011. Rapid rise and fall of selfish sex-ratio X chromosomes in Drosophila simulans: Spatiotemporal analysis of phenotypic and molecular data. Mol Biol Evol 28: 2461-2470.

Bastide H, Gérard PR, Ogereau D, Cazemajor M, Montchamp-Moreau C. 2013. Local dynamics of a fast-evolving sex-ratio system in Drosophila simulans. Mol Ecol 22: 5352-5367.

Beckenbach AT. 1978. The "sex-ratio" trait in Drosophila pseudoobscura: Fertility relations of males and meiotic drive. Am Nat 112: 97-117.

Beckenbach A. 1981. Multiple mating and the "sex-ratio" trait in Drosophila pseudoobscura. Evolution 35: 275-281.

Beckenbach A. 1983. Fitness analysis of the "sex-ratio" polymorphism in experimental populations of Drosophila pseudoobscura. Am Nat 5: 630-648.

Beckenbach AT. 1996. Selection and the "sex-ratio" polymorphism in natural populations of Drosophila pseudoobscura. Evolution 50: 787-794.

Beckenbach AT, Curtsinger JW, Policansky D. 1982. Fruitless experiments with fruit flies: The "sex ratio" chromosomes of D. pseudoobscura. Dros Inf Serv 58: 22.

Bianchi N. 2002. Akodon sex reversed females: The never ending story. Cytogenet Genome Res 96: 60-65.

Branco AT, Tao Y, Hartl DL, Lemos B. 2013. Natural variation of the $\mathrm{Y}$ chromosome suppresses sex ratio distortion and modulates testis-specific gene expression in Drosophila simulans. Heredity 111: 8-15.

Brower-Toland B, Findley SD, Jiang L, Liu L, Yin H, Dus M, Zhou P, Elgin SC, Lin H. 2007. Drosophila PIWI associates with chromatin and interacts directly with HP1a. Genes Dev 21: 2300-2311.

Bryant SH, Beckenbach AT, Cobbs GA. 1982. "Sex-ratio" trait, sex composition, and relative abundance in Drosophila pseudoobscura. Evolution 36: 27-34.

Bull JJ, Charnov EL. 1988. How fundamental are Fisherian sex ratios? Oxford Surv Evol Biol 5: 96-135.

Burt A, Trivers R. 2006. Genes in conflict: The biology of selfish genetic elements. Harvard University Press, Cambridge, MA.

Campbell P, Good JM, Dean MD, Tucker PK, Nachman MW. 2012. The contribution of the Y chromosome to hybrid male sterility in house mice. Genetics 191: 1271-1281.

Capillon C, Atlan A. 1999. Evolution of driving X chromosomes and resistance factors in experimental populations of Drosophila simulans. Evolution 53: 506-517.

Carvalho AB, Vaz SC. 1999. Are Drosophila SR drive chromosomes always balanced? Heredity 83: 221-228.

Carvalho AB, Vaz SC, Klaczko LB. 1997. Polymorphism for Y-linked suppressors of sex-ratio in two natural populations of Drosophila mediopunctata. Genetics 146: $891-$ 902.

Carvalho AB, Sampaio MC, Varandas FR, Klaczko LB. 1998. An experimental demonstration of Fisher's principle: Evolution of sexual proportion by natural selection. Genetics 148: 719-732.

Cazemajor M, Landre C, Montchamp-Moreau C. 1997. The sex-ratio trait in Drosophila simulans: Genetic analysis of distortion and suppression. Genetics 147: 635-642. 
Cazemajor M, Joly D, Montchamp-Moreau C. 2000. Sexratio meiotic drive in Drosophila simulans is related to equational nondisjunction of the $\mathrm{Y}$ chromosome. Genetics 154: 229-236.

Charlesworth B, Dempsey N. 2001. A model of the evolution of the unusual sex chromosome system of Microtus oregoni. Heredity 86: 387-394.

Charlesworth B, Hartl DL. 1978. Population dynamics of the segregation distorter polymorphism of Drosophila melanogaster. Genetics 89: 171-192.

Charlesworth B, Coyne J, Orr H. 1993. Meiotic drive and unisexual hybrid sterility: A comment. Genetics 133: 421.

Chen YS, Racca JD, Sequeira PW, Phillips NB, Weiss MA 2013. Microsatellite-encoded domain in rodent Sry functions as a genetic capacitor to enable the rapid evolution of biological novelty. Proc Natl Acad Sci 110: E3061E3070.

Cheutin T, McNairn AJ, Jenuwein T, Gilbert DM, Singh PB, Misteli T. 2003. Maintenance of stable heterochromatin domains by dynamic HP1 binding. Science 299: $721-$ 725.

Chevin LM, Bastide H, Montchamp-Moreau C, Hospital F. 2009. Molecular signature of epistatic selection: Interrogating genetic interactions in the sex-ratio meiotic drive of Drosophila simulans. Genet Res 91: 171-182.

Chippindale AK, Rice WR. 2001. Y chromosome polymorphism is a strong determinant of male fitness in Drosophila melanogaster. Proc Natl Acad Sci 98: 56775682.

Clark AG. 1987. Natural selection and Y-linked polymorphism. Genetics 115: 569-577.

Cocquet J, Ellis PJ, Mahadevaiah SK, Affara NA, Vaiman D, Burgoyne PS. 2012. A genetic basis for a postmeiotic X versus $\mathrm{Y}$ chromosome intragenomic conflict in the mouse. PLoS Genet 8: e1002900.

Cotton AJ, Földvári M, Cotton S, Pomiankowski A. 2014. Male eyespan size is associated with meiotic drive in wild stalk-eyed flies (Teleopsis dalmanni). Heredity 112: $363-$ 369.

Coyne JA, Rux J, David JR. 1991. Genetics of morphological differences and hybrid sterility between Drosophila sechellia and its relatives. Genet Res 57: 113-122.

Coyne JA, Meyers W, Crittenden AP, Sniegowski P. 1993. The fertility effects of pericentric inversions in Drosophila melanogaster. Genetics 134: 487-496.

Craig GB Jr, Hickey WA, VandeHey RC. 1960. An inherited male-producing factor in Aedes aegypti. Science 132: 1887-1889.

Curtsinger JW, Feldman MW. 1980. Experimental and theoretical analysis of the "sex-ratio" polymorphism in Drosophila pseudoobscura. Genetics 94: 445-466.

De Carvalho AB, Klaczko LB. 1993. Autosomal suppressors of sex-ratio in Drosophila mediopunctata. Heredity 71: $546-546$.

De Carvalho AB, Klaczko LB. 1994. Y-linked suppressors of the sex-ratio trait in Drosophila mediopunctata. Heredity 73: $573-573$.

Deredec A, Godfray HCJ, Burt A. 2011. Requirements for effective malaria control with homing endonuclease genes. Proc Natl Acad Sci 108: E874-E880. de Villena FPM, Sapienza C. 2001. Female meiosis drives karyotypic evolution in mammals. Genetics 159: 11791189.

Dyer KA. 2012. Local selection underlies the geographic distribution of sex-ratio drive in Drosophila neotestacea. Evolution 66: 973-984.

Dyer KA, Charlesworth B, Jaenike J. 2007. Chromosomewide linkage disequilibrium as a consequence of meiotic drive. Proc Natl Acad Sci 104: 1587-1592.

Dyer KA, Bray MJ, Lopez SJ. 2013. Genomic conflict drives patterns of X-linked population structure in Drosophila neotestacea. Mol Ecol 22: 157-169.

Edwards AWF. 1961. The population genetics of "sex-ratio" in Drosophila pseudoobscura. Heredity 16: 291-304.

Espinosa MB, Vitullo AD. 2001. Fast-developing preimplantation embryo progeny from heterogametic females in mammals. Zygote 9: 289-292.

Fisher RA. 1930. The genetical theory of natural selection. Oxford University Press, Oxford.

Fouvry L, Ogereau D, Berger A, Gavory F, Montchamp-Moreau C. 2011. Sequence analysis of the segmental duplication responsible for Paris sex-ratio drive in Drosophila simulans. G3 (Bethesda) 1: 401-410.

Frank SA. 1991. Divergence of meiotic drive-suppression systems as an explanation for sex-biased hybrid sterility and inviability. Evolution 45: 262-267.

Fredga K, Bulmer M. 1988. Aberrant chromosomal sex-determining mechanisms in mammals, with special reference to species with XY females. Phil Trans R Soc Lond B 322: 83-95.

Fredga K, Gropp A, Winking H, Frank F. 1976. Fertile XXand XY-type females in the wood lemming Myopus schisticolor. Nature 261: 225-227.

Gallach M, Betrán E. 2011. Intralocus sexual conflict resolved through gene duplication. Trends Ecol Evol 26: 222-228.

Gell SL, Reenan RA. 2013. Mutations to the piRNA pathway component Aubergine enhance meiotic drive of segregation distorter in Drosophila melanogaster. Genetics 193: 771-784.

Gershenson S. 1928. A new sex-ratio abnormality in Drosophila obscura. Genetics 13: 488.

Gileva E. 1987. Meiotic drive in the sex chromosome system of the varying lemming, Dicrostonyx torquatus Pall. (Rodentia, Microtinae). Heredity 59: 383-389.

Good JM. 2012. The conflict within and the escalating war between the sex chromosomes. PLoS Genet 8: e1002955.

Grewal SI, Bonaduce MJ, Klar AJ. 1998. Histone deacetylase homologs regulate epigenetic inheritance of transcriptional silencing and chromosome segregation in fission yeast. Genetics 150: 563-576.

Gu T, Elgin SCR. 2013. Maternal depletion of Piwi, a component of the RNAi System, impacts heterochromatin formation in Drosophila. PLoS Genet 9: e1003780.

Haig D. 1993a. The evolution of unusual chromosomal systems in coccoids: Extraordinary sex ratios revisited. J Evol Biol 6: 69-77.

Haig D. 1993b. The evolution of unusual chromosomal systems in sciarid flies: Intragenomic conflict and the sex ratio. J Evol Biol 6: 249-261. 
Q. Helleu et al.

Hall DW. 2004. Meiotic drive and sex chromosome cycling. Evolution 58: 925-931.

Hamilton WD. 1967. Extraordinary sex ratios. Science 156: 477-488.

Hartl DL. 1972. Population dynamics of sperm and pollen killers. Theor Appl Genet 42: 81-88.

Hastings I. 1994. Selfish DNA as a method of pest control. Phil Trans R Soc Lond B 344: 313-324.

Hatcher MJ. 2000. Persistence of selfish genetic elements: Population structure and conflict. Trends Ecol Evol 15: 271-277.

Hatcher MJ, Taneyhill DE, Dunn AM, Tofts C. 1999. Population dynamics under parasitic sex ratio distortion. Theor Pop Biol 56: 11-28.

Hauschteck-Jungen E. 1990. Postmating reproductive isolation and modification of the "sex ratio" trait in Drosophila subobscura induced by the sex chromosome gene arrangement A2+3+5+7. Genetica 83: 31-44.

Hauschteck-Jungen E, Maurer B. 1976. Sperm dysfunction in sex ratio males of Drosophila subobscura. Genetica 46: 459-477.

Hickey WA, Craig GB Jr. 1966. Genetic distortion of sex ratio in a mosquito, Aedes aegypti. Genetics 53: 1177.

Hoekstra HE, Hoekstra JM. 2001. An unusual sex-determination system in South American field mice (Genus Akodon): The role of mutation, selection, and meiotic drive in maintaining XY females. Evolution 55: 190-197.

Hurst LD, Pomiankowski A. 1991. Causes of sex ratio bias may account for unisexual sterility in hybrids: A new explanation of Haldane's rule and related phenomena. Genetics 128: 841-858.

Jaenike J. 1996. Sex-ratio meiotic drive in the Drosophila quinaria group. Am Nat 148: 237-254.

Jaenike J. 1999. Suppression of sex-ratio meiotic drive and the maintenance of Y-chromosome polymorphism in Drosophila. Evolution 53: 164-174.

Jaenike J. 2001. Sex chromosome meiotic drive. Annu Rev Ecol Syst 32: 25-49.

Johnson N, Wu CI. 1992. An empirical test of the meiotic drive models of hybrid sterility: Sex-ratio data from hybrids between Drosophila simulans and Drosophila sechellia. Genetics 130: 507-511.

Johnson NA, Hollocher H, Noonburg E, Wu CI. 1993. The effects of interspecific Y chromosome replacements on hybrid sterility within the Drosophila simulans clade. Genetics 135: 443-453.

Kellum R, Alberts BM. 1995. Heterochromatin protein 1 is required for correct chromosome segregation in Drosophila embryos. J Cell Sci 108: 1419-1431.

Kingan SB, Garrigan D, Hartl DL. 2010. Recurrent selection on the Winters sex-ratio genes in Drosophila simulans. Genetics 184: 253-265.

Kovacevic M, Schaeffer SW. 2000. Molecular population genetics of X-linked genes in Drosophila pseudoobscura. Genetics 156: 155-172.

Kozielska M, Weissing F, Beukeboom L, Pen I. 2009. Segregation distortion and the evolution of sex-determining mechanisms. Heredity 104: 100-112.

Lamnissou K, Loukas M, Zouros E. 1996. Incompatibilities between Y chromosome and autosomes are responsible for male hybrid sterility in crosses between Drosophila virilis and Drosophila texana. Heredity 76: 603-609.

Lande R, Wilkinson GS. 1999. Models of sex-ratio meiotic drive and sexual selection in stalk-eyed flies. Genet Res 74: 245-253.

Larracuente AM, Presgraves DC. 2012. The selfish segregation distorter gene complex of Drosophila melanogaster. Genetics 192: 33-53.

Lemos B, Araripe LO, Hartl DL. 2008. Polymorphic Y chromosomes harbor cryptic variation with manifold functional consequences. Science 319: 91-93.

Levine MT, Malik HS. 2013. A rapidly evolving genomic toolkit of Drosophila heterochromatin. Fly 7: 137-141.

Levine MT, McCoy C, Vermaak D, Lee YCG, Hiatt MA, Matsen FA, Malik HS. 2012. Phylogenomic analysis reveals dynamic evolutionary history of the Drosophila heterochromatin protein 1 (HP1) gene family. PLoS Genet 8: e1002729.

Lippman Z, Gendrel AV, Black M, Vaughn MW, Dedhia N, McCombie WR, Lavine K, Mittal V, May B, Kasschau KD, et al. 2004. Role of transposable elements in heterochromatin and epigenetic control. Nature 430: 471-476.

Livak KJ. 1990. Detailed structure of the Drosophila melanogaster stellate genes and their transcripts. Genetics 124: 303.

Lyttle TW. 1977. Experimental population genetics of meiotic drive systems I. Pseudo- $Y$ chromosomal drive as a means of eliminating cage populations of Drosophila melanogaster. Genetics 86: 413-445.

Malik HS, Henikoff S. 2009. Major evolutionary transitions in centromere complexity. Cell 138: 1067-1082.

McDermott SR, Noor MA. 2010. The role of meiotic drive in hybrid male sterility. Phil Trans R Soc Lond B 365: 12651272.

Meiklejohn CD, Tao Y. 2010. Genetic conflict and sex chromosome evolution. Trends Ecol Evol 25: 215-223.

Merçot H, Llorente B, Jacques M, Atlan A, MontchampMoreau C. 1995. Variability within the Seychelles cytoplasmic incompatibility system in Drosophila simulans. Genetics 141: 1015.

Montchamp-Moreau C, Joly D. 1997. Abnormal spermiogenesis is associated with the $\mathrm{X}$-linked sex-ratio trait in Drosophila simulans. Heredity 79: 24-30.

Montchamp-Moreau C, Ginhoux V, Atlan A. 2001. The Y chromosomes of Drosophila simulans are highly polymorphic for their ability to suppress sex-ratio drive. Evolution 55: 728-737.

Montchamp-Moreau C, Ogereau D, Chaminade N, Colard A, Aulard S. 2006. Organization of the sex-ratio meiotic drive region in Drosophila simulans. Genetics 174: $1365-$ 1371.

Morgan TH, Bridges CB, Sturtevant AH. 1925. The genetics of Drosophila. Bibliogr Genet 2: 1-262.

Mueller JL, Mahadevaiah SK, Park PJ, Warburton PE, Page DC, Turner JM. 2008. The mouse X chromosome is enriched for multicopy testis genes showing postmeiotic expression. Nat Genet 40: 794-799.

Namekawa SH, Lee JT. 2009. XY and ZW: Is meiotic sex chromosome inactivation the rule in evolution? PLOS Genet 5: e1000493. 
Navara KJ. 2013. Hormone-mediated adjustment of sex ratio in vertebrates. Integr Comp Biol 53: 877-887.

Newton M, Wood R, Southern D. 1976. A cytogenetic analysis of meiotic drive in the mosquito, Aedes aegypti $(\mathrm{L})$. Genetica 46: $297-318$.

Newton M, Southern D, Wood R. 1978. Relative DNA content of normal and sex-ratio distorting spermatozoa of the mosquito, Aedes aegypti (L.). Chromosoma 67: 253261.

Olszak AM, van Essen D, Pereira AJ, Diehl S, Manke T, Maiato H, Saccani S, Heun P. 2011. Heterochromatin boundaries are hotspots for de novo kinetochore formation. Nat Cell Biol 13: 799-808.

Ortiz MI, Pinna-Senn E, Dalmasso G, Lisanti JA. 2009 Chromosomal aspects and inheritance of the XY female condition in Akodon azarae (Rodentia, Sigmodontinae). Mamm Biol 74: 125-129.

Pal-Bhadra M, Leibovitch BA, Gandhi SG, Rao M, Bhadra U, Birchler JA, Elgin SC. 2004. Heterochromatic silencing and HP1 localization in Drosophila are dependent on the RNAi machinery. Science 303: 669-672.

Parker G. 2006. Sexual conflict over mating and fertilization: An overview. Phil Trans R Soc Lond B 361: 235-259.

Phadnis N, Orr HA. 2009. A single gene causes both male sterility and segregation distortion in Drosophila hybrids. Science 323: 376-379.

Pinzone CA, Dyer KA. 2013. Association of polyandry and sex-ratio drive prevalence in natural populations of Drosophila neotestacea. Proc Biol Sci 280: 20131397.

Policansky D, Ellison J. 1970. "Sex ratio" in Drosophila pseudoobscura: Spermiogenic failure. Science 169: 888-889.

Presgraves D. 2008. Drive and sperm: The evolution and genetics of male meiotic drive. In Sperm biology: An evolutionary perspective (ed. Birkhead TR, et al.), pp. 471506. Academic, London.

Presgraves DC, Severance E, Willrinson GS. 1997. Sex chromosome meiotic drive in stalk-eyed flies. Genetics 147: 1169-1180.

Price TAR, Wedell N. 2008. Selfish genetic elements and sexual selection: Their impact on male fertility. Genetica 134: 99-111.

Price TAR, Hodgson D, Lewis Z, Hurst G, Wedell N. 2008a. Selfish genetic elements promote polyandry in a fly. Science 322: 1241-1243.

Price TAR, Bretman AJ, Avent TD, Snook RR, Hurst GD, Wedell N. 2008b. Sex ratio distorter reduces sperm competitive ability in an insect. Evolution 62: 1644-1652.

Price TAR, Hurst GD, Wedell N. 2010a. Polyandry prevents extinction. Curr Biol 20: 471-475.

Price TAR, Lewis Z, Smith DT, Hurst GD, Wedell N. 2010b. Sex ratio drive promotes sexual conflict and sexual coevolution in the fly Drosophila pseudoobscura. Evolution 64: 1504-1509.

Price TAR, Lewis Z, Smith D, Hurst G, Wedell N. 2012. No evidence of mate discrimination against males carrying a sex ratio distorter in Drosophila pseudoobscura. Behav Ecol Sociobiol 66: 561-568.

Price TAR, Bretman A, Gradilla A, Reger J, Taylor M, Giraldo-Perez P, Campbell A, Hurst G, Wedell N. 2014. Does polyandry control population sex ratio via regulation of a selfish gene? Proc R Soc Lond B 281: 20133259.
Ross BD, Rosin L, Thomae AW, Hiatt MA, Vermaak D, de la Cruz AFA, Imhof A, Mellone BG, Malik HS. 2013. Stepwise evolution of essential centromere function in a Drosophila Neogene. Science 340: 1211-1214.

Rutkowska J, Badyaev AV. 2008. Meiotic drive and sex determination: Molecular and cytological mechanisms of sex ratio adjustment in birds. Phil Trans $R$ Soc Lond B 363: 1675-1686.

Sackton TB, Montenegro H, Hartl DL, Lemos B. 2011. Interspecific Y chromosome introgressions disrupt testisspecific gene expression and male reproductive phenotypes in Drosophila. Proc Natl Acad Sci 108: 1704617051.

Sandler L, Novitski E. 1957. Meiotic drive as an evolutionary force. Am Nat 41: 105-110.

Saunders PA, Perez J, Rahmoun M, Ronce O, Crochet PA, Veyrunes F. 2014. XY females do better than the XX in the African pygmy mouse, Mus minutoides. Evolution doi: 10.1111/evo.12387.

Shakes DC, Neva BJ, Huynh H, Chaudhuri J, Pires-daSilva A. 2011. Asymmetric spermatocyte division as a mechanism for controlling sex ratios. Nat Commun 2: 157.

Shin D, Jin L, Lobo NF, Severson DW. 2011. Transcript profiling of the meiotic drive phenotype in testis of Aedes aegypti using suppressive subtractive hybridization. J Insect Physiol 57: 1220-1226.

Sinkins SP, Gould F. 2006. Gene drive systems for insect disease vectors. Nature Rev Genet 7: 427-435.

Stalker HD. 1961. The genetic systems modifying meiotic drive in Drosophila paramelanica. Genetics 46: 177.

Stapleton W, Das S, McKee BD. 2001. A role of the Drosophila homeless gene in repression of Stellate in male meiosis. Chromosoma 110: 228-240.

Sturtevant A, Dobzhansky T. 1936. Geographical distribution and cytology of "sex ratio" in Drosophila pseudoobscura and related species. Genetics 21: 473.

Tao Y, Hartl DL, Laurie CC. 2001. Sex-ratio segregation distortion associated with reproductive isolation in Drosophila. Proc Natl Acad Sci 98: 13183-13188.

Tao Y, Araripe L, Kingan SB, Ke Y, Xiao H, Hartl DL. 2007a. A sex-ratio meiotic drive system in Drosophila simulans. II: An X-linked distorter. PLoS Biol 5: e293.

Tao Y, Masly JP, Araripe L, Ke Y, Hartl DL. 2007b. A sex-ratio meiotic drive system in Drosophila simulans. I: An autosomal suppressor. PLoS Biol 5: e292.

Taylor DR, Ingvarsson PK. 2003. Common features of segregation distortion in plants and animals. Genetica 117: $27-35$.

Taylor JE, Jaenike J. 2002. Sperm competition and the dynamics of X chromosome drive: Stability and extinction. Genetics 160: 1721-1731.

Taylor JE, Jaenike J. 2003. Sperm competition and the dynamics of $\mathrm{X}$ chromosome drive in finite and structured populations. Ann Zool Fenn 40: 195-206.

Taylor DR, Saur MJ, Adams E. 1999. Pollen performance and sex-ratio evolution in a dioecious plant. Evolution 53: $1028-1036$.

Thomson GJ, Feldman MW. 1975. Population genetics of modifiers of meiotic drive: IV. On the evolution of sexratio distortion. Theor Pop Biol 8: 202-211. 
Q. Helleu et al.

Turner JM. 2007. Meiotic sex chromosome inactivation. Development 134: 1823-1831.

Van Boven M, Weissing FJ. 1999. Segregation distortion in a deme-structured population: Opposing demands of gene, individual and group selection. J Evol Biol 12: $80-93$.

Vaz SC, Carvalho AB. 2004. Evolution of autosomal suppression of the sex-ratio trait in Drosophila. Genetics 166: 265-277.

Veyrunes F, Chevret P, Catalan J, Castiglia R, Watson J, Dobigny G, Robinson TJ, Britton-Davidian J. 2010. A novel sex determination system in a close relative of the house mouse. Proc R Soc Lond B 277: 1049-1056.

Voelker RA. 1972. Preliminary characterization of "sex ratio" and rediscovery and reinterpretation of "male sex ratio" in Drosophila affinis. Genetics 71: 597-606.

Wallace B. 1948. Studies on "sex-ratio" in Drosophila pseudoobscura: I. Selection and "sex-ratio." Evolution 2: 189 217.

Ward MA, Burgoyne PS. 2006. The effects of deletions of the mouse Y chromosome long arm on sperm functionIntracytoplasmic sperm injection (ICSI)-based analysis. Biol Reprod 74: 652-658.

Wedell N. 2013. The dynamic relationship between polyandry and selfish genetic elements. Phil Trans R Soc Lond B 368: 20120049.

West SA, Sheldon BC. 2002. Constraints in the evolution of sex ratio adjustment. Science 295: 1685-1688.

Wilkinson GS, Sanchez MI. 2001. Sperm development, age and sex chromosome meiotic drive in the stalk-eyed fly, Cyrtodiopsis whitei. Heredity 87: 17-24.

Wilkinson GS, Presgraves DC, Crymes L. 1998. Male eye span in stalk-eyed flies indicates genetic quality by meiotic drive suppression. Nature 391: 276-279.

Wilkinson GS, Swallow JG, Christensen SJ, Madden K. 2003. Phylogeography of sex ratio and multiple mating in stalk-eyed flies from southeast Asia. Genetica 117: $37-46$.
Wilkinson G, Johns P, Kelleher E, Muscedere M, Lorsong A. 2006. Fitness effects of $X$ chromosome drive in the stalkeyed fly, Cyrtodiopsis dalmanni. J Evol Biol 19: 18511860.

Wood RJ, Newton ME. 1991. Sex-ratio distortion caused by meiotic drive in mosquitoes. Am Nat 137: 379-391.

Wood R, Ouda N. 1987. The genetic basis of resistance and sensitivity to the meiotic drive gene $\mathrm{D}$ in the mosquito Aedes aegypti L. Genetica 72: 69-79.

Wu CI. 1983a. The fate of autosomal modifiers of the SexRatio trait in Drosophila and other sex-linked meiotic drive systems. Theor Pop Biol 24: 107-120.

Wu CI. 1983b. Virility deficiency and the sex-ratio trait in Drosophila pseudoobscura: I. Sperm displacement and sexual selection. Genetics 105: 651-662.

Wu CI. 1983c. Virility deficiency and the Sex-Ratio trait in Drosophila pseudoobscura: II. Multiple mating and overall virility selection. Genetics 105: 663-679.

Wu CI, Beckenbach AT. 1983. Evidence for extensive genetic differentiation between the sex-ratio and the standard arrangement of Drosophila pseudoobscura and D. persimilis and identification of hybrid sterility factors. Genetics 105: 71-86.

Yang YY, Lin FJ, Chang HY. 2004. Sex ratio distortion in hybrids of Drosophila albomicans and D. nasuta. Zool Stud 43: 622-628.

Yasuno Y, Inoue YH, Yamamoto MT. 2013. Elimination of Y chromosome-bearing spermatids during spermiogenesis in an autosomal sex-ratio mutant of Drosophila simulans. Genes Genet Syst 88: 113-126.

Yoshida K, Kitano J. 2012. The contribution of female meiotic drive to the evolution of neo-sex chromosomes. Evolution 66: 3198-3208.

Zhou J, Sackton TB, Martinsen L, Lemos B, Eickbush TH, Hartl DL. 2012. Y chromosome mediates ribosomal DNA silencing and modulates the chromatin state in Drosophila. Proc Natl Acad Sci 109: 9941-9946. 


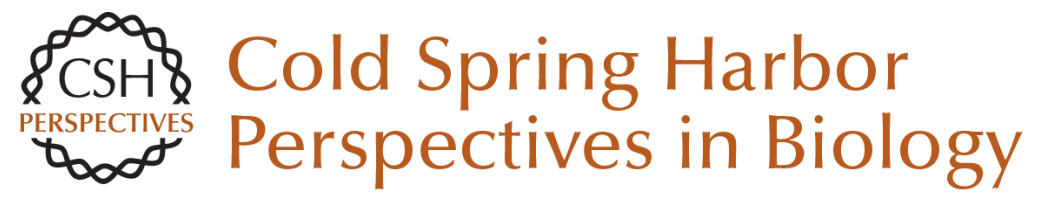

\section{Sex Chromosome Drive}

Quentin Helleu, Pierre R. Gérard and Catherine Montchamp-Moreau

Cold Spring Harb Perspect Biol 2015; doi: 10.1101/cshperspect.a017616 originally published online December 18, 2014

\section{Subject Collection The Genetics and Biology of Sexual Conflict}

Mechanisms and Evidence of Genital Coevolution: The Roles of Natural Selection, Mate Choice, and Sexual Conflict

Patricia L.R. Brennan and Richard O. Prum

The Evolution of Sexually Antagonistic Phenotypes

Jennifer C. Perry and Locke Rowe

Reproductive Parasitism: Maternally Inherited

Symbionts in a Biparental World

Gregory D.D. Hurst and Crystal L. Frost

Sex-Biased Gene Expression and Sexual Conflict throughout Development

Fiona C. Ingleby, Ilona Flis and Edward H. Morrow

Human Homosexuality: A Paradigmatic Arena for

Sexually Antagonistic Selection?

Andrea Camperio Ciani, Umberto Battaglia and Giovanni Zanzotto

Sexual Conflict Arising from Extrapair Matings in Birds

Alexis S. Chaine, Robert Montgomerie and Bruce E. Lyon

Sexual Conflict and Seminal Fluid Proteins: A

Dynamic Landscape of Sexual Interactions

Laura K. Sirot, Alex Wong, Tracey Chapman, et al.

Conflict on the Sex Chromosomes: Cause, Effect, and Complexity

Judith E. Mank, David J. Hosken and Nina Wedell
Infanticide as Sexual Conflict: Coevolution of

Male Strategies and Female Counterstrategies Ryne A. Palombit

Copulatory Wounding and Traumatic Insemination

Klaus Reinhardt, Nils Anthes and Rolanda Lange

Sexual Conflict in Hermaphrodites

Lukas Schärer, Tim Janicke and Steven A. Ramm

Sexual Conflict and Sperm Competition

Dominic A. Edward, Paula Stockley and David J. Hosken

Sexually Antagonistic Zygotic Drive: A New Form of Genetic Conflict between the Sex

Chromosomes

Urban Friberg and William R. Rice

Sex Chromosome Drive

Quentin Helleu, Pierre R. Gérard and Catherine Montchamp-Moreau

Is Sexual Conflict an "Engine of Speciation"? Sergey Gavrilets

Sexual Cannibalism as a Manifestation of Sexual Conflict

Jutta M. Schneider

For additional articles in this collection, see http://cshperspectives.cshlp.org/cgi/collection/

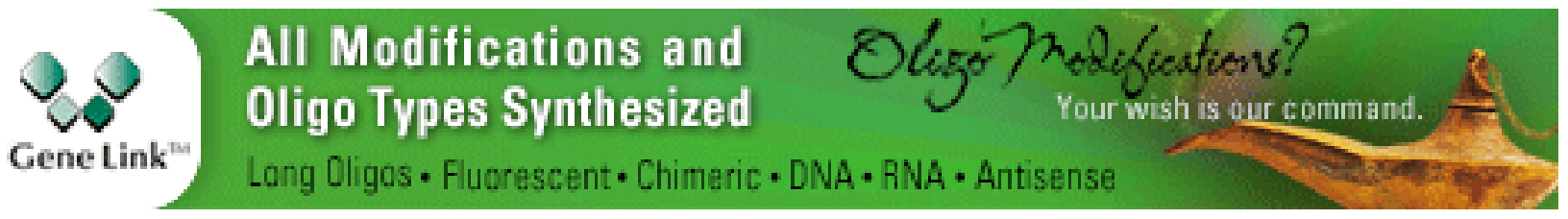

Copyright @ 2015 Cold Spring Harbor Laboratory Press; all rights reserved 
For additional articles in this collection, see http://cshperspectives.cshlp.org/cgi/collection/

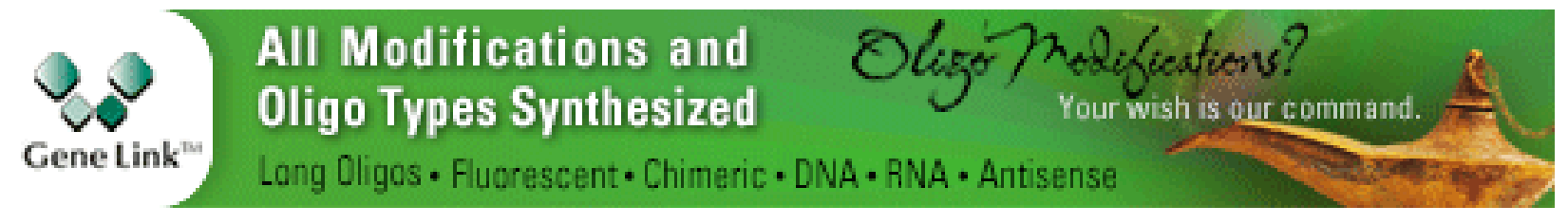

Copyright @ 2015 Cold Spring Harbor Laboratory Press; all rights reserved 